\title{
Early Paralysis for the Management of ARDS
}

\author{
Erin S Grawe MD, Suzanne Bennett MD, and William E Hurford MD
}

\author{
Introduction \\ Pro: NMBAs May Improve Survival in ARDS \\ Mechanisms by Which NMBAs Improve Survival in ARDS \\ Outcomes of NMBA Administration in Early ARDS \\ Con: Early Use of NMBAs May Not Be Indicated Routinely for ARDS \\ Patients \\ Criticisms of ACURASYS Trial \\ Risks Associated With the Use of NMBAs \\ The Appropriate Use of NMBAs in ARDS Patients \\ Summary
}

\begin{abstract}
The use of neuromuscular blocking agents (NMBAs) early in the development of ARDS has been a strategy of interest for many years. The use of NMBAs with a concomitant deep sedation strategy can increase oxygenation and possibly decrease mortality when used in the early stages of ARDS. The mechanism by which this occurs is unclear but probably involves a combination of factors, such as improving patient-ventilator synchrony, decreasing oxygen consumption, and decreasing the systemic inflammatory response associated with ARDS. The use of NMBA and deep sedation for these patients is not without consequence. This discussion describes the rationale and evidence behind the use of NMBAs in the setting of ARDS. Key words: ARDS; adult; neuromuscular blocking agents; mechanical ventilation; paralysis. [Respir Care 2016;61(6):830-838. (C) 2016 Daedalus Enterprises]
\end{abstract}

\section{Introduction}

Sedatives, opioids, and neuromuscular blocking agents (NMBAs) are commonly used medications in the ICU. Their administration is meant to achieve comfort and

The authors are affiliated with the Department of Anesthesiology, University of Cincinnati College of Medicine, Cincinnati, Ohio.

The authors have disclosed no conflict of interest.

Dr Hurford presented a version of this report at the 54th RESPIRATORY CARE Journal Conference on Respiratory Care Controversies III, held June 5 and 6, 2015, in St. Petersburg, Florida.

Correspondence: William E Hurford MD, Department of Anesthesiology, University of Cincinnati College of Medicine, PO Box 670531, 231 Albert Sabin Way, Cincinnati, OH 45267-0531. E-mail: bill.hurford@uchealth.com.

DOI: $10.4187 /$ respcare.04734 maintain safety in mechanically ventilated patients. Excessive sedation, however, may prolong the length of mechanical ventilation and increase the risk of complications in intubated patients. ${ }^{1,2}$ The dilemma we face in caring for critically ill patients is the balance between maintaining patient comfort while minimizing the adverse outcomes of our therapies. Inherent to the use of mechanical ventilation is a subset of patients who can become asynchronous with the ventilator, particularly when the severity of a patient's illness increases. Appropriate patient-ventilator interaction is of paramount importance. Asynchrony between the patient and the mechanical ventilator can contribute to patient discomfort and dyspnea, ${ }^{3}$ increase work of breathing, increase respiratory muscle fatigue, and produce measurement errors in the assessment of breathing frequency and readiness to wean. Difficulties with weaning translate into worse outcomes in the ICU, including prolonged mechanical ventilation time, increased stay in the ICU, increased muscle 
injury, increased risk of tracheostomy, and even an increase in mortality. ${ }^{4-8}$ Optimizing patient-ventilator interaction to minimize asynchrony can require the use of larger doses of sedatives and NMBAs, a practice that is inconsistent with our goals of minimizing sedation.

Management of ARDS remains a challenge in the ICU. Despite what we have learned regarding lung-protective ventilation strategies with low tidal volumes, ARDS still carries a high mortality rate. ${ }^{9} 10$ Strategies such as prone positioning ${ }^{11-14}$ and targeting higher than traditional PEEP to achieve an open lung have some limited evidence of therapeutic effectiveness. ${ }^{15,16}$ The use of NMBAs early in the development of ARDS has been a strategy of interest for the last decade. There is convincing evidence that the use of NMBAs with a concomitant deep sedation strategy can increase oxygenation and possibly decrease mortality when used in the early stages of ARDS. ${ }^{17-19}$ The mechanism by which this occurs is unclear but probably involves a combination of factors, such as improving patient-ventilator synchrony, decreasing oxygen consumption, and decreasing the systemic inflammatory response associated with ARDS. ${ }^{18,20,21}$ The use of NMBAs and subsequently deep sedation for these patients is not without consequence. The following discussion will describe the rationale and evidence behind the use of NMBAs and the potential risks involved in the setting of ARDS.

\section{Pro: NMBAs May Improve Survival in ARDS}

\section{Mechanisms by Which NMBAs Improve Survival in ARDS}

ARDS continues to be a major source of morbidity and mortality. It affects approximately 190,000 patients annually in the United States and is associated with a mortality estimated at $>40 \% .{ }^{10}$ ARDS is an inflammatory disease process characterized by diffuse bilateral pulmonary edema, decreased lung compliance, and hypoxemia. ${ }^{6}$ The only well-established therapy for ARDS is the supportive use of lung-protective mechanical ventilation strategies aimed at minimizing further lung damage by limiting tidal volumes and decreasing mean airway pressures. ${ }^{9}$ Until recently, there has not been any specific pharmacologic therapy shown to improve mortality or outcomes in ARDS. In a randomized controlled trial of 340 subjects with severe ARDS, however, Papazian et al in the ACURASYS trial ${ }^{18}$ reported that the use of NMBAs early in the course of treatment decreased the duration of mechanical ventilation and improved survival. The major causes of death in patients with ARDS are severe hypoxemia and multi-system organ failure, secondary to infection, sepsis, hemodynamic instability, and ventilator-induced lung injury. ${ }^{6} \mathrm{It}$ is important to examine how the use of NMBAs can influence this pathophysiology.
Reduced pulmonary compliance and diffusion limitations secondary to edema and inflammation at the alveolar-capillary level, which result in hypoxemia and hypercarbia, are hallmarks of ARDS. Without paralysis, hypoxemia and hypercarbia stimulate respiratory drive, which can lead to increased tidal volumes, active exhalation, and patient-ventilator asynchrony. ${ }^{6}$ With improved patient-ventilator synchrony with the administration of NMBAs, tidal volumes can be tightly regulated, thus decreasing the barotrauma and volutrauma caused by overdistention of alveoli from high tidal volume ventilation. Limiting active exhalation with paralysis also allows for better control over PEEP, thereby reducing atelectotrauma or injury due to repetitive opening and closing of lung units. Patient-ventilator asynchrony can be caused by several different mechanisms, including ineffective inspiratory effort during the exhalation cycle, double-triggering (breath-stacking), inappropriate cycling, and aborted inspiration. ${ }^{8}$ These asynchronies occur when patients are more interactive with the ventilator and oftentimes air-hungry, a common scenario for a patient with ARDS. The result of asynchrony is ineffective ventilation and increased airway pressures, both of which are detrimental to a lung-protective mechanical ventilation strategy. In an observational study, Blanch et $\mathrm{al}^{8}$ measured an asynchrony index in 50 subjects mechanically ventilated on various modes of mechanical ventilation. The asynchrony index was based on the number of asynchronous events a subject had with the ventilator in a given hour. They reported that an asynchrony index of $<10 \%$ (compared with those $>10 \%$ ) was associated with decreased ICU and hospital mortality and a trend toward shorter duration of mechanical ventilation. ${ }^{8}$ NMBAs can eliminate this asynchrony by removing patient effort and allowing the ventilator to control the triggering and cycling of breaths.

Severe hypoxemia contributes to the mortality associated with ARDS. NMBAs improve oxygenation in ARDS. In a randomized controlled trial of 56 subjects with ARDS, Gainnier et $\mathrm{al}^{17}$ examined the effects of NMBAs on oxygenation parameters. Compared with placebo, subjects who received NMBAs for $48 \mathrm{~h}$ early in the course of ARDS had significantly improved $\mathrm{P}_{\mathrm{aO}_{2}} / \mathrm{F}_{\mathrm{IO}_{2}}$ after $48 \mathrm{~h}$. This effect persisted for several days beyond discontinuation of the NMBA. The NMBA group also had faster weaning of PEEP, indicating improved lung compliance at the end of the 5-d study period. ${ }^{17}$ A separate randomized trial by Forel et al ${ }^{21}$ reported similar improvements in oxygenation with the use of NMBAs in early ARDS..$^{21}$ The mechanism for improved oxygenation remains unclear. It may be a result of improved ventilation-perfusion relationships that occur with the initiation of muscle paralysis and the ability to maintain consistent levels of PEEP throughout all lung fields. ${ }^{6}$ There is some evidence that muscle paralysis or 
even deep sedation with a Ramsay score of $<6$ reduces the oxygen consumption by ventilatory muscles. $22-24$ The reduction in oxygen consumption might decrease demand for oxygen delivery and carbon dioxide removal, ultimately resulting in decreased cardiac output and decreased pulmonary blood flow, which then may minimize the edema seen at the alveolar-capillary level in ARDS. What is interesting to note is that for both the Gainnier et $\mathrm{al}^{17}$ and Forel et $\mathrm{al}^{21}$ trials, the improvement in oxygenation persisted throughout the 5-d study period, well beyond the $48 \mathrm{~h}$ of muscle paralysis, ${ }^{17,21}$ which suggests that the reduction in oxygen consumption cannot be the primary mechanism of improved oxygenation.

Another mechanism in which NMBAs could improve survival in ARDS may involve an anti-inflammatory effect. The lungs of a patient with ARDS are subject to overinflation and overstretching by mechanical ventilation, which may produce biotrauma, a regional and systemic inflammatory response that may generate or amplify multi-system organ failure. Causes of biotrauma include repetitive opening and closing of atelectatic lung units, surfactant alterations, loss of alveolar-capillary barrier, and bacterial translocation. ${ }^{25}$ In animal models of ARDS, Imai et $\mathrm{a}^{26}$ found that high tidal volume low PEEP mechanical ventilation can increase inflammatory markers and rates of apoptosis in the kidney and small intestine, which suggested a multi-system organ response to varying strategies of mechanical ventilation. The trial by Forel et $\mathrm{al}^{21}$ of NMBAs in ARDS evaluated inflammatory cytokine levels in the serum and bronchoalveolar lavage samples of subjects randomized to NMBA versus placebo. They reported that bronchoalveolar lavage levels of interleukin (IL)-8, IL-6, and IL-1B and serum levels of IL-6 and IL-1B were lower in the NMBA group at $48 \mathrm{~h}$ after randomization. ${ }^{21}$

One explanation of the efficacy of NMBAs in decreasing this inflammatory response is that paralysis induces greater homogeneity of the distribution of PEEP and tidal volume. This would reduce de-recruitment of dependent lung areas and minimize the repetitive opening and closing of atelectatic lung units and perhaps limit inflammatory mediator release normally associated with de-recruitment and atelectasis. ${ }^{21}$ Cisatracurium may also have a primary receptor-mediated anti-inflammatory effect on cells. ${ }^{6}$ The clinical importance of this effect, however, remains unclear at this point.

\section{Outcomes of NMBA Administration in Early ARDS}

So the question remains: If NMBAs can decrease inflammation, improve oxygenation, and improve patientventilator asynchrony in patients with ARDS, does this translate to improved outcomes in the ICU? To date, Papazian et $\mathrm{al}^{18}$ have performed the largest randomized controlled study, the ACURASYS trial, to help answer this question. They conducted a multi-center, placebocontrolled, double-blind study of 340 subjects with ARDS (defined as a $\mathrm{P}_{\mathrm{aO}_{2}} / \mathrm{F}_{\mathrm{IO}_{2}}$ of $<150$ with a PEEP of $\geq 5 \mathrm{~cm} \mathrm{H}$ and a tidal volume of $6-8 \mathrm{~mL} / \mathrm{kg}$ ideal body weight) to determine whether a short period of treatment with cisatracurium early in the course of severe ARDS would improve clinical outcomes. The baseline characteristics between the treatment and control arms were similar with the exception that the cisatracurium group had a lower baseline mean $\mathrm{P}_{\mathrm{aO}_{2}} / \mathrm{F}_{\mathrm{IO}_{2}}$ ratio compared with placebo, 106 versus $115(P=.03)$, respectively. The primary end point was 90-d mortality. Using the Cox multivariate regression model and adjusting for baseline $\mathrm{P}_{\mathrm{aO}_{2}} / \mathrm{F}_{\mathrm{IO}_{2}}$, plateau pressure, and Simplified Acute Physiology Score II, they found that the hazard ratio for death at $90 \mathrm{~d}$ in the cisatracurium group, as compared with placebo, was 0.68 (95\% CI $0.48-$ $0.98, P=.04)$. In crude analysis, the $90-\mathrm{d}$ mortality rate in the cisatracurium group was $31 \%$ (95\% CI $25-38 \%$ ) compared with $40 \%$ in the placebo group (95\% CI 33-48\%), $P=.08$. The improved survival in the cisatracurium group was limited to the two thirds of subjects presenting with a $\mathrm{P}_{\mathrm{aO}_{2}} / \mathrm{F}_{\mathrm{IO}_{2}}$ of $<120$.

Secondary outcomes evaluated were ventilator days, ICU stay, number of organ or system failures, barotrauma, ICUacquired paresis, and muscle strength as evaluated by the Medical Research Council scale. The cisatracurium group had more ventilator-free days than the placebo group during the first 28 and $90 \mathrm{~d}(10.6 \mathrm{~d}$ vs $8.5 \mathrm{~d}, P=.04,53.1 \mathrm{~d}$ vs $44.6 \mathrm{~d}, P=.03$ ) and more days spent outside of the ICU within the first $90 \mathrm{~d}$ compared with placebo (47.7 vs 39.5 , $P=.03$ ). The cisatracurium group had a decrease in the number of days without organ failure compared with placebo when assessing coagulation abnormalities, hepatic failure, and renal failure, but these differences were not statistically significant. Pneumothorax occurred in a larger percentage in the placebo group (11\% vs $4 \%$ in the cisatracurium group, $P=.04$ ). Before the development of pneumothorax in either study group, none of the subjects had an elevated plateau pressure necessitating changes in management. The incidence of ICU-acquired paresis as evaluated by the Medical Research Council scale on day 28 or at time of ICU discharge did not differ significantly between the 2 study groups.

\section{Con: Early Use of NMBAs May Not Be Indicated Routinely for ARDS Patients}

\section{Criticisms of ACURASYS Trial}

Although the results of the ACURASYS trial are very encouraging, we must consider that, although the trial included 340 subjects, it is statistically under-powered to evaluate mortality. According to the authors, 885 subjects should be needed to achieve $80 \%$ statistical power. ${ }^{18}$ In 


\section{EARLY PARALYSIS FOR ARDS}

addition, the survival benefit was limited to those subjects with $\mathrm{P}_{\mathrm{aO}_{2}} / \mathrm{F}_{\mathrm{IO}_{2}}$ of $<120$, further limiting statistical strength. The study also has not been reproduced in other multicenter randomized trials and has not been attempted with other NMBAs besides cisatracurium.

Critics of the ACURASYS trial argue that if one of the major benefits of NMBAs is the improvement in patient-ventilator synchrony, then it would have been advantageous for the study to monitor and assess patient-ventilator interactions to determine a causal relationship. Hence, the relationship remains speculative. One can argue that the incidence of patient-ventilator asynchrony may not be as high as expected in the ARDS population. ${ }^{27}$ Epstein ${ }^{28}$ reported that only $30 \%$ of ARDS subjects suffered from ineffective ventilator triggering compared with subjects with respiratory failure from other mechanisms. ${ }^{27,28}$ If the incidence of asynchrony is low, then intervention with NMBAs may not be advantageous. If asynchrony is problematic in a patient with ARDS, then other non-pharmacologic interventions might effectively improve patient-ventilator dynamics.

For example, Chanques et al, ${ }^{29}$ evaluating mechanically ventilated subjects in the ICU, reported that $26 \%$ exhibited severe breath-stacking asynchrony with a mean asynchrony index of $44 \%$. Management options included no intervention, increasing sedation/analgesia, or making a ventilator adjustment. Compared with baseline, the decrease in asynchrony index was greater after adjusting ventilator settings than after increasing sedation/analgesia $(P<.001)$ or deciding to tolerate asynchrony $(P<.001)$. The transition to pressure-support ventilation and increased inspiratory time were independently associated with a reduction in asynchrony index. ${ }^{29}$ In the ACURAYS trial, all subjects were mechanically ventilated in a volume assist-control mode, and this mode was not adjusted for the sake of blinding. All subjects were sedated to a Ramsay score of 6 (no response to glabelar tap) before the initiation of treatment. If there were sustained episodes of elevated end-inspiratory plateau pressure $>32 \mathrm{~cm} \mathrm{H}_{2} \mathrm{O}$, which can occur during episodes of asynchrony, then tidal volume and PEEP levels were adjusted, sedation was increased, and openlabel cisatracurium was bolused, but the mode of ventilation was never changed. ${ }^{18}$ It is conceivable that inadequate management of asynchrony in the placebo group could have predisposed to worse outcomes.

Another concern in the ACURASYS trial is that depth of neuromuscular blockade was not monitored. The use of a train-of-four peripheral nerve simulator is generally considered a standard of care for managing and titrating the effect of neuromuscular blockade. Due to obvious blinding considerations, monitoring of train-of-four was not done in this study. As a result, adequacy and duration of neuromuscular blockade in the treatment group can be called into question. There are reports of tachyphylaxis and re- sistance to neuromuscular blockade in critically ill patients. ${ }^{30,31}$ Thus, it is possible that the benefits observed in the cisatracurium group were independent of neuromuscular blockade.

\section{Risks Associated With the Use of NMBAs}

There are inherent risks to the use of NMBAs in patients in the ICU. Unrecognized ventilator disconnections can quickly lead to hypoxemia and hypercarbia and cause cardiopulmonary collapse. Inadequate sedation and analgesia in a paralyzed patient can cause extreme psychologic distress. As an example, Nelson et $\mathrm{al}^{32}$ investigated the relationship between the use of NMBAs during acute lung injury and the quality of life of survivors in a retrospective study of 24 subjects questioned after treatment in the ICU. Post-traumatic stress disorder symptoms were positively correlated with days of sedation and days of NMBA use but not with severity of illness. The inhibition of a cough reflex can lead to poor secretion clearance and mucus plugging that can cause increased airway pressures and hypoxemia if not effectively addressed. Patients are more at risk for corneal abrasion and ulceration given their inability to blink; thus, artificial tears should be applied intermittently, and eyes should be taped shut to prevent drying. During the period of paralysis, neurologic evaluation is not possible; therefore, recognition of neurologic deterioration during this time will be delayed.

Prolonged paralysis after discontinuation of NMBAs, defined as an increase in the time to recovery of 50 to $100 \%$ longer than predicted by pharmacologic parameters, is a problem encountered specifically after prolonged infusions on NMBAs and more commonly reported in the steroid-based NMBAs, including pancuronium, vecuronium, and rocuronium. ${ }^{33-35}$ This is primarily due to the accumulation of NMBAs or their metabolites. ${ }^{36}$ Steroidbased NMBAs undergo extensive hepatic metabolism, producing active drug metabolites, some of which can be $80 \%$ as potent as the parent compound. These active drug metabolites are renally excreted; thus, accumulation of parent drug and active metabolites is enhanced in the setting of hepatic and/or renal dysfunction. ${ }^{36}$ Drug-drug interactions can also potentiate depth of motor blockade and may prolong recovery. Drugs that are implicated include local anesthetics, aminoglycoside antimicrobials, calcium channel blockers, magnesium, diuretics, lithium, and antiarrhythmics, including procainamide and quinidine. ${ }^{36}$

Whether NMBAs contribute to ICU-acquired weakness is still under debate. What is known is that critical illness polyneuropathy and critical illness myopathy are responsible for significant morbidity in critically ill patients. Research for the last 2 decades has shown that critical illness polyneuropathy and myopathy can affect up to $50 \%$ of the ICU population. They present as limb and respiratory mus- 


\section{EARLY PARALYSIS FOR ARDS}

Table 1. Available Neuromuscular Blocking Agents

\begin{tabular}{|c|c|c|c|c|}
\hline Agent & Active Metabolite & Metabolism & Elimination & Adverse Effects \\
\hline Pancuronium & Yes & Liver & Renal excretion & Vagolytic \\
\hline Vecuronium & Yes & Liver & Renal excretion & None \\
\hline Rocuronium & No & Liver & Renal excretion & None \\
\hline Atracurium & No & No & Hofmann elimination & Histamine release \\
\hline Cisatracurium & No & No & Hofmann elimination & None \\
\hline
\end{tabular}

cle weakness and, even with improvement, can cause varying degrees of disability after discharge from the hospital, from subtle weakness with limitation in exercise tolerance to profound disability. ${ }^{37,38}$ Sepsis, systemic inflammatory response syndrome, and multi-organ failure are risk factors for critical illness polyneuropathy and myopathy. A systematic review of published work showed evidence of critical illness polyneuropathy and myopathy in $46 \%$ (95\% CI 43-49) of adult ICU subjects who had lengthy mechanical ventilation, sepsis, or multi-organ failure. ${ }^{39}$ Risk factors have been discussed in the literature. In a prospective cohort study of mechanically ventilated ICU subjects, De Jonghe et al ${ }^{40}$ identified independent risk factors for the development of ICU-acquired weakness, which include female sex, multiple organ dysfunctions, duration of mechanical ventilation, and administration of corticosteroids. Duration of vasopressor support, duration of ICU stay, hyperglycemia, low serum albumin, and neurological failure have also been identified as risk factors. ${ }^{41,42}$ With respect to NMBAs, the literature is contradictory. In a cohort study of 73 septic subjects with multi-organ dysfunction syndrome requiring mechanical ventilation, Garnacho-Montero et $\mathrm{al}^{43}$ reported that $63 \%$ of subjects developed critical illness polyneuropathy as diagnosed by electrophysiologic studies. Of the subjects diagnosed with critical illness polyneuropathy, $18 \%$ of them received NMBAs during their ICU stay. After multivariate analysis, they determined that the use of NMBAs was independently associated with the development of critical illness polyneuropathy ${ }^{43}$ Griffiths and Hall ${ }^{44}$ reported that simultaneous use of NMBAs and corticosteroids could be associated with muscle weakness, whereas NMBA use alone was not identified as an independent risk factor. Other studies, however, have not been able to support the relationship between NMBAs and development of critical illness polyneuropathy and myopathy. $18,40,42,45,46$ What we have learned from the literature is that immobility has profound effects on skeletal muscle and is a risk factor for muscle weakness during critical illness. ${ }^{38}$ The use of NMBAs can certainly increase the duration of immobility, but the evidence to implicate it as an independent risk factor for prolonged disability is not definitive.

\section{The Appropriate Use of NMBAs in ARDS Patients}

The choice of NMBA and how it is utilized is critical. The ideal neuromuscular blocker would have a titratable effect, rapid onset and offset of paralysis to allow for neurological assessments, no adverse hemodynamics or physiologic adverse effects, hepatic and renal functionindependent elimination, inactive metabolites, and reasonable cost. The available NMBAs in the United States are pancuronium, vecuronium, rocuronium, atracurium, and cisatracurium (Table 1). Since the combination of longterm high-dose corticosteroids and prolonged NMBAs, particularly the steroidal NMBAs, could increase the likelihood of developing an acute myopathy, ${ }^{34,44}$ attempts should be made to avoid the steroidal NMBA (vecuronium, rocuronium, pancuronium) infusions. Vecuronium has active metabolites. Pancuronium, vecuronium, and rocuronium undergo hepatic metabolism and renal elimination to varying degrees. Both atracurium and pancuronium have adverse effects. Both atracurium and cisatracurium undergo Hoffman elimination, an organ-independent spontaneous degradation, which is temperature- and plasma $\mathrm{pH}$ dependent. Cisatracurium is free of active metabolites and adverse effects, making it an appealing NMBA. To date, no study has definitively compared the use of different NMBAs in ARDS subjects.

In addition to the choice of NMBA, the method of utilization of NMBA can impact outcomes (Table 2). The use of NMBAs in ARDS should be rare, but when used, attempts should be made to minimize their dose and duration. ${ }^{47}$ Initiation and duration should be limited to the first $48 \mathrm{~h}$ in severe ARDS with discontinuation as soon as possible. In an effort to limit NMBA dosing, depth of blockade should be guided by peripheral neuromuscular monitoring. The train-of-four, obtained from the peripheral neuromuscular monitor, goal is to achieve and maintain 1 to 2 twitches. In a prospective, randomized singleblind trial of 77 critically ill subjects receiving continuous NMBA, dosing guided by clinical response versus peripheral neuromuscular monitoring resulted in less drug per hour and total drug used. Subjects who underwent peripheral neuromuscular monitoring recovered neuromuscular 


\section{EARLY PARALYSIS FOR ARDS}

Table 2. Recommendations for the Use of Neuromuscular Blocking Agents in ARDS Patients

The use of neuromuscular blockade should be rare.

Consider other efforts to reduce patient-ventilator asynchrony before considering paralysis.

Limit the duration of neuromuscular blockade (should have little need beyond $48 \mathrm{~h}$ ).

Avoid administration of corticosteroids with steroidal NMBAs (eg, vecuronium, pancuronium).

Titrate dosage according to physical signs and routine peripheral neuromuscular monitoring.

NMBAs = neuromuscular blocking agents

Table 3. Supportive Care in Patients Receiving Neuromuscular Blocking Agents

Ensure adequate sedation and analgesia before neuromuscular blockade.

Turn the patient frequently and pad pressure points to avoid pressure ulcers.

Elevate the head of the bed to decrease risk of aspiration.

Perform tracheal suction based on secretions, since the patient will not have a cough reflex.

Monitor closely for ventilator disconnections and circuit malfunctions.

Regularly apply eye lubrication and/or cover eyelids to avoid corneal abrasions.

function (relative risk 1.89) and spontaneous ventilation (relative risk $2.27,95 \% \mathrm{CI}$ of $1.23-4.21, P=.019$ ) faster than control subjects. ${ }^{48}$ When NMBAs are used, ensure adequate sedation and analgesia before neuromuscular blockade, frequent turning and pressure point padding, elevation of the head of bed $>30$ degrees, suctioning to clear secretions, close supervision and avoidance of ventilator disconnections, and application of eye care to avoid corneal abrasions (Table 3).

\section{Summary}

Convincing evidence exists that suggests the use of NMBAs in the setting of ARDS can have a positive impact on mortality, ventilator days and ICU length of stay. The most promising application has been with its early use (within $48 \mathrm{~h}$ of development of ARDS), and in those patients with severe disease $\left(\mathrm{P}_{\mathrm{aO}_{2}} / \mathrm{F}_{\mathrm{IO}_{2}}<120\right)$. Potential mechanisms by which this occurs are multifactorial and include improving patient-ventilator synchrony, improving oxygenation, decreasing oxygen consumption, and decreasing the systemic inflammatory response associated with ARDS. The application of NMBAs, and the deep sedation that is required with their use, however, is certainly not without consequence. Some of the risks associated with this practice include prolonged mechanical ventilation due to ex- cessive sedation, prolonged paralysis after discontinuation of NMBAs, development of critical illness myopathy and neuropathy, development of corneal abrasions and ulcerations, and risk of apnea with unrecognized ventilator disconnections. As clinicians, we continuously have to balance the risks and benefits associated with our therapies and adjust our treatment strategies. If NMBAs are used in the setting of severe ARDS, we recommend limiting their duration of use to $48 \mathrm{~h}$, avoiding administration of corticosteroids with steroidal NMBAs, and titrating their dosage according to physical signs and routine use of peripheral nerve monitoring.

\section{REFERENCES}

1. Arroliga AC, Thompson BT, Ancukiewicz M, Gonzales JP, Guntupalli KK, Park PK, et al. Use of sedatives, opioids, and neuromuscular blocking agents in patients with acute lung injury and acute respiratory distress syndrome. Crit Care Med 2008;36(4):1083-1088.

2. Kollef MH, Levy NT, Ahrens TS, Schaiff R, Prentice D, Sherman G. The use of continuous IV sedation is associated with prolongation of mechanical ventilation. Chest 1998;114(2):541-548.

3. Schmidt M, Demoule A, Polito R, Porchet R, Aboab J, Siami S, et al. Dyspnea in mechanically ventilated critically ill patients. Crit Care Med 2011;39(9):2059-2065.

4. de Wit M, Miller KB, Green DA, Ostman HE, Gennings C, Epstein SK. Ineffective triggering predicts increased duration of mechanical ventilation. Crit Care Med 2009;37(10):2740-2745.

5. Thille AW, Rodriguez P, Cabello B, Lellouche F, Brochard L. Patient-ventilator asynchrony during assisted mechanical ventilation. Intensive Care Med 2006;32(10):1515-1522.

6. Slutsky AS. Neuromuscular blocking agents in ARDS. N Engl J Med 2010;363(12):1176-1180.

7. Vassilakopoulos T, Petrof BJ. Ventilator-induced diaphragmatic dysfunction. Am J Respir Crit Care Med 2004;169(3):336-341.

8. Blanch L, Villagra A, Sales B, Montanya J, Lucangelo U, Luján M, et al. Asynchronies during mechanical ventilation are associated with mortality. Intensive Care Med 2015;41(4):633-641.

9. ARDS Definition Task Force, Ranieri VM, Rubenfeld GD, Thompson BT, Ferguson ND, Caldwell E. Acute respiratory distress syndrome: the Berlin Definition. JAMA 2012;307(23):2526-2533.

10. Rubenfeld GD, Caldwell E, Peabody E, Weaver J, Martin DP, Neff $\mathrm{M}$, et al. Incidence and outcomes of acute lung injury. N Engl J Med 2005;353(16):1685-1693.

11. Mancebo J, Fernández R, Blanch L, Rialp G, Gordo F, Ferrer M, et al. A multicenter trial of prolonged prone ventilation in severe acute respiratory distress syndrome. Am J Respir Crit Care Med 2006;173(11):1233-1239.

12. Gattinoni L, Tognoni G, Pesenti A, Taccone P, Mascheroni D, Labarta $\mathrm{V}$, et al. Effect of prone positioning on the survival of patients with acute respiratory failure. N Engl J Med 2001;345(8):568-573.

13. Guérin C, Reignier J, Richard JC, Beuret P, Gacouin A, Boulain T, et al. Prone positioning in severe acute respiratory distress syndrome. N Engl J Med 2013;368(23):2159-2168.

14. Taccone P, Pesenti A, Latini R, Polli F, Vagginelli F, Mietto C, et al Prone positioning in patients with moderate and severe acute respiratory distress syndrome: a randomized controlled trial. JAMA 2009; 302(18): 1977-1984.

15. Brower RG, Lanken PN, MacIntyre N, Matthay MA, Morris A, Ancukiewicz M, et al. Higher versus lower positive end-expiratory pressures in patients with the acute respiratory distress syndrome. N Engl J Med 2004;351(4):327-336. 


\section{EARLY PARALYSIS FOR ARDS}

16. Briel M, Meade M, Mercat A, Brower RG, Talmor D, Walter SD, et al. Higher vs lower positive end-expiratory pressure in patients with acute lung injury and acute respiratory distress syndrome: systematic review and meta-analysis. JAMA 2010;303(9):865-873.

17. Gainnier M, Roch A, Forel JM, Thirion X, Arnal JM, Donati S, Papazian L. Effect of neuromuscular blocking agents on gas exchange in patients presenting with acute respiratory distress syndrome. Crit Care Med 2004;32(1):113-119.

18. Papazian L, Forel JM, Gacouin A, Penot-Ragon C, Perrin G, Loundou A, et al. Neuromuscular blockers in early acute respiratory distress syndrome. N Engl J Med 2010;363(12):1107-1116.

19. Alhazzani W, Alshahrani M, Jaeschke R, Forel JM, Papazian L, Sevransky J, Meade MO. Neuromuscular blocking agents in acute respiratory distress syndrome: a systematic review and meta-analysis of randomized controlled trials. Crit Care 2013;17(2):R43.

20. Freebairn RC, Derrick J, Gomersall CD, Young RJ, Joynt GM. Oxygen delivery, oxygen consumption, and gastric intramucosal $\mathrm{pH}$ are not improved by a computer-controlled, closed-loop, vecuronium infusion in severe sepsis and septic shock. Crit Care Med 1997; 25(1):72-77.

21. Forel JM, Roch A, Marin V, Michelet P, Demory D, Blache JL, et al. Neuromuscular blocking agents decrease inflammatory response in patients presenting with acute respiratory distress syndrome. Crit Care Med 2006;34(11):2749-2757.

22. Terao Y, Miura K, Saito M, Sekino M, Fukusaki M, Sumikawa K. Quantitative analysis of the relationship between sedation and resting energy expenditure in postoperative patients. Crit Care Med 2003;31(3):830-833.

23. Hubmayr RD, Abel MD, Rehder K. Physiologic approach to mechanical ventilation. Crit Care Med 1990;18(1):103-113.

24. Manthous CA, Hall JB, Kushner R, Schmidt GA, Russo G, Wood LD. The effect of mechanical ventilation on oxygen consumption in critically ill patients. Am J Respir Crit Care Med 1995;151(1):210-214.

25. Slutsky AS. Lung injury caused by mechanical ventilation. Chest 1999;116(1 Suppl):9S-15S.

26. Imai Y, Parodo J, Kajikawa O, de Perrot M, Fischer S, Edwards V, et al. Injurious mechanical ventilation and end-organ epithelial cell apoptosis and organ dysfunction in an experimental model of acute respiratory distress syndrome. JAMA 2003;289(16):2104-2112.

27. Nava S, Bruschi C, Fracchia C, Braschi A, Rubini F. Patient-ventilator interaction and inspiratory effort during pressure support ventilation in patients with different pathologies. Eur Respir J 1997; 10(1):177-183.

28. Epstein SK. How often does patient-ventilator asynchrony occur and what are the consequences? Respir Care 2011;56(1):25-38.

29. Chanques G, Kress JP, Pohlman A, Patel S, Poston J, Jaber S, Hall JB. Impact of ventilator adjustment and sedation-analgesia practices on severe asynchrony in patients ventilated in assist-control mode. Crit Care Med 2013;41(9):2177-2187.

30. Haddad S. Tachyphylaxis to cisatracurium: case reports and literature review. Middle East J Anaesthesiol 2008;19(5):1079-1092.

31. Tschida SJ, Graupe KJ, Hoey LL, Vance-Bryan K. Resistance to nondepolarizing neuromuscular blocking agents. Pharmacotherapy 1996;16(3):409-418.

32. Nelson BJ, Weinert CR, Bury CL, Marinelli WA, Gross CR. Intensive care unit drug use and subsequent quality of life in acute lung injury patients. Crit Care Med 2000;28(11):3626-3630.
33. Lagasse RS, Katz RI, Petersen M, Jacobson MJ, Poppers PJ. Prolonged neuromuscular blockade following vecuronium infusion. J Clin Anesth 1990;2(4):269-271.

34. Margolis BD, Khachikian D, Friedman Y, Garrard C. Prolonged reversible quadriparesis in mechanically ventilated patients who received longterm infusions of vecuronium. Chest 1991;100(3):877-878.

35. Segredo V, Caldwell JE, Matthay MA, Sharma ML, Gruenke LD, Miller RD. Persistent paralysis in critically ill patients after long-term administration of vecuronium. N Engl J Med 1992;327(8):524-528.

36. Murray MJ, Cowen J, DeBlock H, Erstad B, Gray AW Jr, Tescher $\mathrm{AN}$, et al. Clinical practice guidelines for sustained neuromuscular blockade in the adult critically ill patient. Crit Care Med 2002;30(1): 142-156.

37. Hraiech S, Forel JM, Papazian L. The role of neuromuscular blockers in ARDS: benefits and risks. Curr Opin Crit Care 2012;18(5): 495-502.

38. Latronico N, Bolton CF. Critical illness polyneuropathy and myopathy: a major cause of muscle weakness and paralysis. Lancet Neurol 2011;10(10):931-941.

39. Stevens RD, Dowdy DW, Michaels RK, Mendez-Tellez PA, Pronovost PJ, Needham DM. Neuromuscular dysfunction acquired in critical illness: a systematic review. Intensive Care Med 2007;33(11): 1876-1891.

40. De Jonghe B, Sharshar T, Lefaucheur JP, Authier FJ, Durand-Zaleski I, Boussarsar M, et al. Paresis acquired in the intensive care unit: a prospective multicenter study. JAMA 2002;288(22):28592867.

41. Witt NJ, Zochodne DW, Bolton CF, Grand'Maison F, Wells G, Young GB, Sibbald WJ et al. Peripheral nerve function in sepsis and multiple organ failure. Chest 1991;99(1):176-184.

42. Van den Berghe G, Schoonheydt K, Becx P, Bruyninckx F, Wouters PJ. Insulin therapy protects the central and peripheral nervous system of intensive care patients. Neurology 2005;64(8):1348-1353.

43. Garnacho-Montero J, Madrazo-Osuna J, García-Garmendia JL, Ortiz-Leyba C, Jiménez-Jiménez FJ, Barrero-Almodóvar A, et al. Critical illness polyneuropathy: risk factors and clinical consequences: a cohort study in septic patients. Intensive Care Med 2001;27(8):12881296.

44. Griffiths RD, Hall JB. Intensive care unit-acquired weakness. Crit Care Med 2010;38(3):779-787.

45. Bednarík J, Vondracek P, Dusek L, Moravcova E, Cundrle I. Risk factors for critical illness polyneuromyopathy. J Neurol 2005;252(3): 343-351.

46. de Letter MA, Schmitz PI, Visser LH, Verheul FA, Schellens RL, Op de Coul DA, van der Meché FG. Risk factors for the development of polyneuropathy and myopathy in critically ill patients. Crit Care Med 2001;29(12):2281-2286.

47. Bennett S, Hurford WE. When should sedation or neuromuscular blockade be used during mechanical ventilation? Respir Care 2011; 56(2):168-176; discussion 176-180.

48. Rudis MI, Sikora CA, Angus E, Peterson E, Popovich J, Jr, Hyzy R, Zarowitz BJ. A prospective, randomized, controlled evaluation of peripheral nerve stimulation versus standard clinical dosing of neuromuscular blocking agents in critically ill patients. Crit Care Med 1997;25(4):575-583. 


\section{Discussion}

Marini: Bill, nice review. I know that Papazian's group ${ }^{1}$ initially reported that cisatracurium has an antiinflammatory effect. Has anybody else corroborated those observations?

\section{Hurford: Not to my knowledge.}

Berra: There was an anti-inflammatory study ${ }^{2}$ in a septic animal model.

Kacmarek: I thought there were a couple references in Art's editorial? ${ }^{3}$ To the anti-inflammatory effects, at least in some models?

Kallet: I was also interested in the high dose of cisatracurium and the antiinflammatory effects. If it's not that, one thing that comes to mind is possibly inhibiting pro-inflammatory mediator release from the respiratory muscles. Compared to other skeletal muscles, the diaphragm has a higher baseline production of pro-inflammatory mediators. ${ }^{4}$ I'm not sure why, but it does. I was looking up some articles on athletes and pro-inflammatory mediator release, which doesn't directly apply, but strenuous muscular exercise produces a substantial amount of pro-inflammatory mediators. 5,6 So someone rigid, struggling, and breathing like crazy, it might be that we take that out of the equation. In fact, it's been shown that increased respiratory muscle loads cause an intense inflammatory response. ${ }^{7}$ Bill, could you address this? Do you think the mortality difference would be seen early on? Because the separation in mortality is around 3 weeks. That's kind of hard to interpret; it's not what I would expect to see using early paralysis in ARDS.

Marini: I have exactly the same question ... and maybe a hypothesis to explain that observation. Could it be that we are programmed by evolution to die when we get this sick? In other words, from an evolutionary standpoint because somebody this sick is not likely to survive and might be a little weaker than the others, take them out of the reproduction circuit. Our body systems might not be geared to respond to severe, life-threatening stress in a constructive way. So, if there were a catastrophic positive feedback loop that was interrupted by taking control, the mortality difference might be expected to emerge some time after the neuromuscular blockade was used. In most studies of ARDS, subjects tend to die in the 2-3 week window. But it's rare to have a study where everybody's mortality risk is identical for the first week to $10 \mathrm{~d}$ and then the groups separate sharply at day 15 or 16. Is there some signal we're interrupting early on? In other words, do we slow the freight train of dysfunction brought on by the early excessive response - and by doing that affect mediators, anti-inflammatory effects and all that kind of stuff? Maybe any anti-inflammatory property of cisatracurium is dose-related, too. I don't think that we know that.

Hurford: All excellent comments and certainly I don't know the answers. The question about the antiinflammatory effect of cisatracurium is that it would be very bizarre that this would be the one anti-inflammatory of the last 3 decades that is so effective after the use of general inflammatory drugs such as high-dose steroids and such have not had that benefit. I remain unconvinced. But there's no question that it could be. It's very difficult to prove or disprove and to tease that out.

Kacmarek: Art talks in his editorial ${ }^{3}$ about recent articles dealing with asynchrony and all the issues associated with it. In those articles, subjects don't die early, either. Like in Lluís Blanch's recent study ${ }^{8}$ death was not immediate, it was weeks later when these subjects were dying. So maybe breaking that cycle that you see in early severe
ARDS where patients are really fighting the ventilator, they have significant hemodynamic issues and we don't have time or capability to stabilize them, paralyzing them for that period of time perhaps minimizes injury and allows for more rapid stabilization.

Hurford: The other way to think about that is we are pretty good at keeping people alive if we want to. So, as that cycle progresses on to renal failure, coagulopathy, liver failure, coma, that takes some time. And that final mode of death is usually limitation of further support or aggressive therapy rather than a catastrophic event.

Kallet: Dale Needham did a retrospective study ${ }^{9}$ about ARDS Net management in the Baltimore area and found that the degree of adherence to lung-protective ventilation actually affected mortality 1-2 y out from the advent of ARDS. Which is not really explained, but it suggests that something happens very early on that we don't know about. In doing the paper on hyperoxia for this presentation, there were some studies on exposure to hyperoxia in neonates showing that it has an impact on disease development many years later in life. Maybe some genetic alteration occurs that gets turned on or can't be turned off. It will be intriguing to see what happens in the next 20 years when they do more research on that. Obviously something is going on.

Kacmarek: Let me ask a question. Do we need to paralyze for $48 \mathrm{~h}$ or do we need to paralyze until we establish stability? And how frequently do we need to reassess and lighten it up or reverse the paralysis and determine whether or not we need to keep going?

Hurford: I don't know.

Kacmarek: That's not a good answer! 
Hurford: I'll tell you what I think, rather than what I know. I think, as I recommended in my talk, to use it as short a time as possible.

Kacmarek: I agree.

Hurford: I think, too, if a patient can be managed in a synchronous fashion and is not struggling or fighting the ventilator that using other modalities or deeper sedation rather than neuromuscular blockade is reasonable. I think if you can't manage a patient without paralyzing them for a week then it's way past time for an extracorporeal membrane oxygenation (ECMO) consult.

Kacmarek: I tend to agree with you, but remember that the control arm in the Papazian study ${ }^{10}$ was to sedate them heavily to apnea.

Hurford: That's actually pretty hard to do.

Kacmarek: The argument is there was breakthrough, the subjects were fighting the ventilator and nobody noticed it and all these things were going on that didn't happen under neuromuscular blockade. I don't know. I'm asking the question because I don't know either - what is the right thing to do?
Hurford: Our clinical practice is to not replicate what Papazian did.

Kacmarek: That's pretty much the decision we've made. Evaluate on a patient-by-patient basis, use it for as short a time as possible, and discontinue it as soon as you possibly can.

Hurford: Our clinical process is also to use paralysis if a patient is so asynchronous or so hypoxemic that they can't be managed without it.

MacIntyre: I just want to clarify, so if they're comfortable with a $\mathrm{P}_{\mathrm{O}_{2}}$ of 100 they don't get paralytics?

Hurford: In our practice, that's correct.

\section{References}

1. Forel JM, Roch A, Marin V, Michelet P, Demory D, Blache JL, et al. Neuromuscular blocking agents decrease inflammatory response in patients presenting with acute respiratory distress syndrome. Crit Care Med 2006;34(11):2749-2757.

2. Jiang J, Yang B, Han G, Yang M, Li S. Early administration of cisatracurium attenuates sepsis-induced diaphragm dysfunction in rats. Inflammation 2015;38(1): 305-311.

3. Slutsky AS. Neuromuscular blocking agents in ARDS. NEJM 2010;363(12): 1176-1180.
4. Demoule A, Divangahi M, Yahiaoui L, Danialou G, Gvozdic D, Labbe K, et al. Endotoxin triggers nuclear factor- $\kappa \mathrm{B}$ dependent up-regulation of multiple proinflammatory genes in the diaphragm. Am J Respir Crit Care Med 2006;174(6): 646-653.

5. Vaisberg M, de Mello MT, Seelaender MCL, dos Santos RVT, Costa Rosa LF. Reduced maximal oxygen consumption and overproduction of proinflammatory cytokines in athletes. Neuroimmunomodulation 2007;14(6):304-309.

6. Pedersen BK, Ostrowski K, Rohde T, Bruunsgaard $\mathrm{H}$. The cytokine response to strenuous exercise. Can J Physiol Pharmacol 1998;76(5):505-511.

7. Jiang TX, Reid WD, Belcastro A, Road JD. Load dependence of secondary diaphragm inflammation and injury after acute inspiratory loading. Am J Respir Crit Care Med 1998;157(1):230-236.

8. Blanch L, Villagra A, Sales B, Montanya J, Lucangelo U, Luján M, et al. Asynchronies during mechanical ventilation are associated with mortality. Intensive Care Med 2015;41(4):633-641.

9. Needham DM, Colantouni E, MendezTellez PA, Dinglas VD, Sevransky JE, Dennison Himmelfarb CR, et al. Lung protective mechcanical ventiolation and two year survival in patients with acute lung injury: prospective cohort study. BMJ 2012;344: e2124.

10. Papazian L, Forel JM, Gacouin A, PenotRagon C, Perrin G, Loundou A, et al; ACURASYS Study Investigators. Neuromuscular blocking agents in early acute respiratory distress syndrome. N Engl J Med 2010;363(12):1107-1116. 